\title{
backstory
}

\section{Saudi Arabian volcano crisis}

\section{John S. Pallister and Wendy A. McCausland rushed to the aid of their Saudi Arabian colleagues to advise on an emerging earthquake emergency.}

\section{What was the starting point of the work?}

Our colleagues at the Saudi Geological Survey asked for assistance from the US Geological Survey when an energetic earthquake swarm hit the country in May 2009 and produced a dramatic 8-km-long fault rupture across a volcanic field near the Red Sea margin. The Saudi Geological Survey had conducted an effective rapid response, quickly deployed field teams and installed a broadband seismic monitoring network that transferred data to their observatory in Jeddah. They had also located earthquakes and advised civil defence authorities of the potential hazards. In response to their request, the US Geological Survey sent a two-person team to Saudi Arabia to assist during the crisis. We worked together with our Saudi colleagues to obtain and interpret deformation data, and to forecast and communicate potential hazards. After the crisis was over, we continued our collaboration.

\section{Why did you choose this location?} We did not choose the location, the location chose us! The earthquakes took place at Harrat Lunayyir, one of the youngest of a series of plateau basalt fields in Saudi Arabia. The swarm peaked in intensity on 19 to 20 May 2009 with several events of magnitudes 4 to 5 , which fractured walls in a nearby town. Concern that there could be larger and more damaging earthquakes led the Saudi Government to evacuate 40,000 people from the region. Everyone wanted to know if there would be an eruption or larger earthquakes.

\section{What sort of data were you after?}

We began by analysing the available seismic data to see if the earthquakes had the characteristics of a volcanic swarm (they did). We also obtained spectacular ground

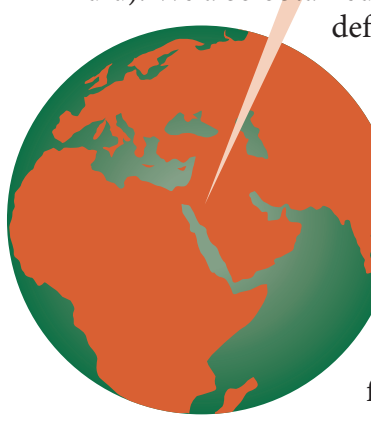

eformation data

from radar satellite

interferometry that indicated dyke intrusion. Finally we investigated the history of eruptive and seismic activity in the region as context for our forecasts.

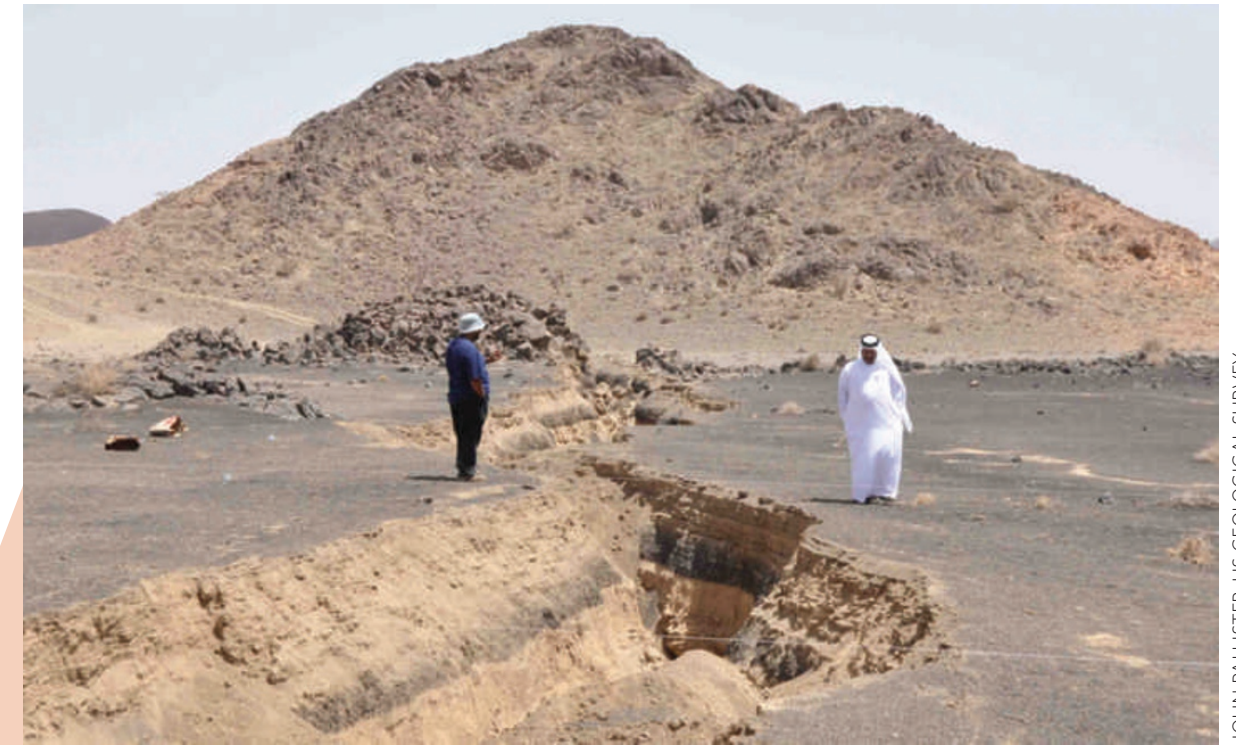

The team walk the entire length of the fault trace that cut sediments and basalts within the Harrat Lunayyir volcanic field, Saudi Arabia.

Did you encounter any difficulties? Working under the pressure of a crisis, in which many people rely on your scientific judgment for their safety, always produces stress, but our response went smoothly. This pressure is a common issue faced by volcano observatories worldwide, and the Saudi and US teams worked effectively together.

\section{Any highlights?}

We flew the full length of the 8-km rupture by helicopter, at heights of only a few tens of metres, which allowed us to observe changes as the fault crossed different rock types. And we hiked along the trace of the fault to a mountain pass where the fault offsets basement rocks. We searched this region for pairs of piercing points - and we found one: a small acacia bush had been split and offset by the fault! By measuring the offset, we documented the absolute motion of the fault. From a personal perspective, a fantastic, albeit rushed, fish dinner we had together with our Saudi Arabian colleagues at a site where we could see the Sun set over the Red Sea was a particular highlight, as was a visit with our Saudi hosts to the old suk (marketplace) in Jeddah.
Did the trip give you any ideas for future research projects?

Absolutely! The seismic and deformation data clearly illustrate that a magmatic dyke was intruded beneath the volcanic field. Such events are not thought to be common in Saudi Arabia, but this occurrence raises the likelihood of a future eruption, and illustrates the need for further monitoring and research. More research is needed on the activity of the extensive lava fields of Arabia, especially in areas experiencing rapid urban growth, such as near the holy city of Madinah where an eruption took place in AD 1256. As a result, the Saudi Geological Survey is expanding its volcano monitoring and research programme, and the Saudi and US Geological Surveys are discussing plans for future collaborations. Furthermore, the Lunayyir swarm included unusual earthquakes with seismic wave components at high and very low frequencies, but lacking in intermediate frequencies. A detailed seismic analysis of these events is underway.

This is the backstory to the work by Pallister and colleagues, published on page 705 of this issue. 